Southern Illinois University Carbondale

OpenSIUC

Publications

Center for Fisheries, Aquaculture, and Aquatic

Sciences

$11-2019$

\title{
Natal Environments of Age-0 Paddlefish in the Middle Mississippi River Inferred from Dentary Microchemistry
}

Neil P. Rude

Southern Illinois University Carbondale, nrude@siu.edu

Gregory Whitledge

Southern Illinois University Carbondale, gwhit@siu.edu

Follow this and additional works at: https://opensiuc.lib.siu.edu/fiaq_pubs

\section{Recommended Citation}

Rude, Neil P. and Whitledge, Gregory. "Natal Environments of Age-0 Paddlefish in the Middle Mississippi River Inferred from Dentary Microchemistry." River Research and Applications 35, No. 9 (Nov 2019): 1554-1562. doi:10.1002/rra.3526.

This Article is brought to you for free and open access by the Center for Fisheries, Aquaculture, and Aquatic Sciences at OpenSIUC. It has been accepted for inclusion in Publications by an authorized administrator of OpenSIUC. For more information, please contact opensiuc@lib.siu.edu. 


\title{
NATAL ENVIRONMENTS OF AGE-0 PADDLEFISH IN THE MIDDLE MISSISSIPPI RIVER INFERRED FROM DENTARY MICROCHEMISTRY
}

\author{
Neil P. Rude ${ }^{1}$ and Gregory W. Whitledge \\ Center for Fisheries, Aquaculture, and Aquatic Sciences, Southern Illinois University, \\ 1125 Lincoln Drive, Carbondale, IL, 62901, USA
}

${ }^{1}$ Present address: Minnesota Department of Natural Resources, 1801 S. Oak Street, Lake City, MN, 55041, USA

This is the peer reviewed version of the following article: [Rude, N.P. and G.W. Whitledge. 2019. Natal environments of age-0 Paddlefish in the middle Mississippi River inferred from dentary microchemistry. River Research and Applications 35:1554-1562.], which has been published in final form at: [https://onlinelibrary.wiley.com/doi/10.1002/rra.3526]. This article may be used for noncommercial purposes in accordance with Wiley Terms and Conditions for Use of Self-Archived Versions. 


\begin{abstract}
Effective management and conservation of riverine fish species relies on identification of habitats that contribute recruits to fish populations. Paddlefish are an important commercial and recreational species inhabiting North American large rivers. However, despite knowledge of adult paddlefish movement patterns in large rivers, their principal natal environments and early life dispersal patterns remain unknown. Paddlefish dentary microchemistry can be used to identify natal environment of fish in large river networks such as the middle Mississippi River (MMR) and tributaries. The goals of this study were to (1) use dentary microchemistry (strontium:calcium ratios; $\mathrm{Sr}: \mathrm{Ca}$ ) to determine natal environment and potential drift for age-0 paddlefish collected from the MMR, and (2) assess whether MMR river reach or year of collection influenced the percentage of recruits originating from different rivers. Age-0 paddlefish were collected during 2010-2011 from two reaches of the MMR (upstream and downstream of the Kaskaskia River confluence). Water samples from the MMR and tributaries (upper Mississippi, Missouri, Illinois, Osage, and Kaskaskia rivers) were collected during 20062016. Water Sr:Ca differed among rivers, enabling identification of natal environment for individual fish using dentary core Sr:Ca. The MMR (44-69\% of fish sampled) and Missouri River (25-45\% of fish sampled) were the primary natal environments for age-0 paddlefish across both river reaches and collection years. The upper Mississippi River and smaller tributaries contributed few recruits ( $<13 \%$ of fish sampled). Conservation of paddlefish populations should include maintenance or improvement of connectivity between river reaches used for spawning and juvenile rearing and stock assessments of riverine paddlefish may need to be conducted at a riverscape scale because multiple rivers can contribute to paddlefish recruitment in a particular river reach.
\end{abstract}


KEY WORDS: Polyodon spathula, origin, larval drift, Sr:Ca, Mississippi River, early life history 


\section{INTRODUCTION}

Effective management and conservation of riverine fish species relies on identification of critical habitats used for spawning, refuge, and foraging (Fausch et al., 2002). In particular, knowledge of geographic areas that contribute recruits to adult stocks, and dispersal patterns of fish from natal environments is fundamental to understanding riverine fish metapopulations (Hanski and Gilpin, 1997) and identifying relevant spatial scales for population assessment (Cooke et al., 2016). Many adult large-bodied riverine species migrate long distances for reproduction and foraging (Pracheil et al., 2012; Tripp et al., 2014; Phelps et al., 2016; Porreca et al., 2016; Tripp et al., 2019). However, knowledge of spawning locations and subsequent natal dispersal and habitat use by young of year is often limited, despite their importance for informing efforts to maintain or rehabilitate habitats (e.g., locations with suitable depth, flow, and substrate for spawning or habitats conducive to growth and survival of age-0 fish; Phelps et al., 2009) and connectivity between those habitats that collectively support recruitment in riverine fish populations.

Paddlefish Polyodon spathula is a large, long-lived commercially and recreationally important large river specialist found in the Mississippi, Ohio, and Missouri river basins and their principal tributaries (Hupfeld et al., 2016). Paddlefish were once abundant throughout their range but populations have experienced declines due to commercial and recreational overfishing, habitat degradation, and fragmentation of river networks by dams (Scholten and Bettoli, 2005; Bettoli et al., 2009). As a result of these population declines, many states prohibit commercial and recreational harvest of paddlefish (Bettoli et al., 2009; Hupfeld et al., 2016). However, adult paddlefish are highly migratory and individuals migrate long distances (> $2000 \mathrm{~km})$ among rivers and across state (and management) boundaries (Stancill et al., 2002; Pracheil et al., 2012; 
Tripp et al., 2014; Tripp et al., 2019). The potential for long migrations of paddlefish individuals from locations with protective regulations to locations without protective regulations has prompted a movement towards interjurisdictional management to protect this highly migratory species (Pracheil et al., 2012; Hupfeld et al., 2016; Tripp et al., 2019). However, despite the knowledge of adult paddlefish movement, and the potential conservation actions to protect paddlefish, little is known about their natal origins and early life dispersal patterns (Phelps et al., 2009; Bock et al., 2016).

Age-0 paddlefish are subject to downstream drift in large river systems like many other large river specialist species, such as sturgeons (Jennings, 2009). Drift of age-0, large river specialist fish species is dependent on fin formation time after hatch, river current velocities, and substrate (Braaten et al., 2008). Drift distance of paddlefish has not been assessed, but previous research on fish that have similar early life history to paddlefish (e.g., Scaphirhynchus sturgeons; Braaten et al., 2008; Jennings, 2009) suggests individuals may drift > $500 \mathrm{~km}$ in the Missouri and Mississippi River systems (Braaten et al., 2008; Phelps et al., 2012). Because fin formation occurs multiple days post-hatch in both paddlefish and Scaphirhynchus sturgeons (Davis et al., 2004; Braaten et al., 2008; Phelps et al., 2012), paddlefish may be subjected to similar drift dynamics as Scaphirhynchus sturgeons in these large river systems. For example, Phelps et al. (2012) documented that some age-0 Scaphirhynchus sturgeon collected in the middle Mississippi River (MMR; segment of the Mississippi River between its confluences with the Missouri and Ohio rivers) likely originated from the Missouri River $>589 \mathrm{~km}$ upstream from collection site. Therefore, it is possible that age- 0 paddlefish collected from the MMR may potentially originate from far upstream in the Missouri or upper Mississippi rivers or other tributaries. However, traditional tracking methods for adult paddlefish, such as telemetry and tagging, are not feasible 
for age- 0 individuals. Collecting wild age- 0 paddlefish soon after hatch may prove especially difficult, and affixing tags to age-0 individuals for tracking is problematic due to the small size of these fish (Brown et al., 1999; Jepsen et al., 2005).

Microchemical analyses of paddlefish dentary bones may provide an alternative to traditional techniques for determining drift and movement of age-0 paddlefish (Bock et al., 2016). Microchemical analyses of fish hard-part structures have been used to identify recruitment sources and reconstruct environmental histories of fish (Kennedy et al., 2002; Smith and Whitledge, 2011; Bock et al., 2016), including large river specialist species (Laughlin et al., 2016; Porreca et al., 2016). Large rivers and their tributaries often have distinct elemental signatures (Zeigler and Whitledge, 2010, 2011; Laughlin et al., 2016; Wuellner et al., 2017; Abell et al., 2018; Whitledge et al., 2019), and the hard-part elemental signature reflects the water in which they reside (Kennedy et al., 2002; Smith and Whitledge, 2011; Bock et al., 2016). For example, Laughlin et al. (2016) used otolith microchemistry analyses to determine that blue catfish Ictalurus furcatus and channel catfish I. punctatus stocks in the MMR were supported by drift or movement of age- 0 fish from the Missouri River ( $>53 \%$ in blue catfish, and $>31 \%$ in channel catfish). Similarly, fin ray microchemistry of age-0 Scaphirhynchus sturgeon collected from the MMR indicated that $30 \%$ of individuals sampled exhibited natal river signatures of the Missouri River (both upper >589 km upstream of the Missouri-Mississippi River confluence, and lower reaches) (Phelps et al., 2012). Although no published studies have applied hard-part microchemistry to infer environmental history of wild paddlefish, paddlefish dentary bone elemental composition is strongly related to that of the water in which the fish reside (Bock et al., 2016), suggesting that this technique could be used to infer natal origin and drift of age-0 paddlefish in rivers. Therefore, the objectives of this study were to (1) determine the natal 
environment (river of origin) and potential drift for age-0 paddlefish collected from the MMR using dentary microchemistry, and (2) assess whether MMR river reach or year of collection influenced percentage of recruits originating from different rivers. Understanding paddlefish natal environment and drift is important for identifying recruitment sources, assessing linkages between natal and juvenile nursery locations, and evaluating the extent of mixing among paddlefish stocks, all of which are crucial for effective conservation and management of the species, particularly with respect to restoring or maintaining habitats used during critical early life periods.

\section{METHODS}

\section{Study area}

The MMR is a $309 \mathrm{~km}$ unimpounded section of the river extending from the confluence of the Missouri and Mississippi rivers to the Ohio River-Mississippi River confluence (Figure 1). This study area encompassed the entire MMR reach and included adjacent large tributaries that support adult paddlefish populations and contain habitats needed for spawning (Jennings, 2009). Tributaries included the Upper Mississippi River (UMR), Missouri River (MOR), and smaller tributaries including the Illinois River, Kaskaskia River, and Osage River (Figure 1). Fish collection locations were split into two reaches of the MMR to assess potential differences in recruitment sources between reaches. The first reach (reach 1) extended from the confluence of MOR with the Mississippi River to the Kaskaskia River-Mississippi River confluence, and the second reach (reach 2) was downstream of the mouth of the Kaskaskia River to the Ohio RiverMississippi River confluence (Figure 1).

\section{Water collection and analyses}


Water samples were taken from the MMR and tributaries used in this study for strontium (Sr) and calcium $(\mathrm{Ca})$ concentrations to characterize $\mathrm{Sr}$ :Ca signatures for each river. Other natural markers commonly used in studies of fish hard-part microchemistry (e.g., Ba:Ca, $\mathrm{Mg}: \mathrm{Ca}, \mathrm{Mn}: \mathrm{Ca}$, ${ }^{87} \mathrm{Sr} /{ }^{86} \mathrm{Sr}$ ) were not used in this study, as they either do not differ among rivers considered to be potential natal locations for age-0 paddlefish in the MMR or do not provide additional capability of distinguishing among rivers that differ in water Sr:Ca (Zeigler and Whitledge, 2011; Whitledge, unpublished). Water samples were collected monthly during mid-June to midOctober 2006 through 2016 to verify persistence of differences in Sr:Ca signatures of the MMR, MOR, and tributaries. Water samples were collected using a syringe filtration technique described by Shiller (2003) and stored on ice until analyses of Sr and Ca concentrations at the Center for Trace Analysis, University of Southern Mississippi. Samples were acidified and diluted with $0.16 \mathrm{M}$ ultrapure nitric acid $\left(\mathrm{HNO}_{3}\right.$; Shiller, 2003). The $\mathrm{HNO}_{3}$ contained $2 \mathrm{ppb}$ scandium, indium, and thorium as internal standards. External certified reference standards for $\mathrm{Sr}$ and $\mathrm{Ca}$ were also prepared using the same $\mathrm{HNO}_{3}$ used for sample dilutions. Water samples were analyzed for ${ }^{44} \mathrm{Ca}$ and ${ }^{88} \mathrm{Sr}$ in high resolution using a Thermo-Finnigan Element 2 (Thermo Fisher Scientific, Waltham, MA, USA) inductively coupled plasma mass spectrometer. Precision of analyses based on repeated measurements of standards was $\pm 2 \%$ (2 SD). Elemental concentrations for water samples were converted to molar Sr:Ca ratios $(\mathrm{mmol} / \mathrm{mol})$ so that paddlefish dentary $\mathrm{Sr}: \mathrm{Ca}$ for each potential natal river could be estimated using a regression relating water and dentary Sr:Ca (Bock et al., 2016).

\section{Dentary collection, preparation, and analyses}

Age-0 paddlefish were collected throughout the MMR during early spring (April-May) through mid-summer (July) 2010 and 2011 using benthic trawls (Herzog et al., 2005). Each site was 
sampled with three 1-minute trawls, including a shallow site $(<3 \mathrm{~m})$, a moderately deep site (3-6 $\mathrm{m}$ ), and a deep site (> $6 \mathrm{~m}$ ). A total of 143 age-0 paddlefish were collected in the MMR, including 50 fish from reach 1 and 93 individuals from reach 2 (Table 1). All paddlefish were measured to the nearest mm eye-fork length (EFL), and individuals $<200 \mathrm{~mm}$ EFL were collected, euthanized with MS-222, placed on ice for transport to the laboratory, and stored frozen until dentary removal.

A portion of the dentary was removed from each fish by cutting at the anterior end of the lower jaw with diagonal pliers, and making a second cut posterior to the point of greatest curvature in the dentary bone along one side of the jaw, thus including a large portion of the straight section of the dentary bone (Adams, 1942; Scarnecchia et al., 2006; Bock et al., 2016). Any skin adhering to the dentary was removed using forceps and a scalpel. Although metallic pliers, forceps, and scalpels were used, they did not come into contact with the cross-sectioned surface of the dentary bone that was analyzed for Sr:Ca. Dentary bones were air-dried prior to sectioning.

Dentary bones were embedded in Epo-fix epoxy (Electron Microscopy Sciences Inc., Hatfield, PA, USA), and sectioned using a Buehler IsoMet (Buehler Inc., Lake Bluff, IL, USA) low-speed saw to $1.2 \mathrm{~mm}$ sections posterior to the point of greatest curvature. Sections were sanded using $\mathrm{AlO}_{2}$ paper (800 and 1000 grit), and polished with lapping film. Sanded and polished sections were mounted to microscope slides using double-sided tape, ultrasonically cleaned for $5 \mathrm{~min}$ in ultrapure water, and dried for $24 \mathrm{~h}$ under a laminar flow hood. Mounted and cleaned dentaries were stored in polypropylene Petri dishes in a sealed container until analyses. Sectioned dentaries were analyzed for $\mathrm{Sr}$ and $\mathrm{Ca}$ concentrations using a Perkin-Elmer DRC II (Perkin-Elmer Life and Analytical Sciences, Shelton, CT, USA) inductively coupled mass 
spectrometry coupled with a CETAC Technologies (Teledyne CETAC Technologies, Omaha, NE, USA) LSX-213 laser ablation system. The laser ablated a transect extending from the dentary core (earliest material grown) to its edge along the long axis of the mesial limb of the dentary bone (laser beam diameter $=50 \mu \mathrm{m}$, scan rate $=5 \mu \mathrm{m} / \mathrm{s}$, laser pulse rate $=20 \mathrm{~Hz}$, laser energy level $=9 \mathrm{~mJ}, 7$ data points per second; Bock et al., 2016). Two standards developed by the U.S. Geological Survey (microanalytical carbonate standard; MACS-1 and microanalytical phosphate standard; MAPS-1) were analyzed every 12-15 samples to adjust for possible instrument drift. Several studies investigating bone and fin ray chemistry have used glass or $\mathrm{CaCO}_{3}$ standards (e.g., Phelps et al., 2012; Woodcock et al., 2013; Rude et al., 2014; Bock et al., 2016) despite the fact that these are not perfectly matrix-matched with fin ray or other bone samples. Each sample was proceeded by a 60 -s gas blank measurement. Isotopic counts were converted to elemental concentrations ( $\mu \mathrm{g} / \mathrm{g}$ ) after correction for gas blank, matrix, and drift effects (Ludsin et al., 2006). Mean limit detection for ${ }^{88} \mathrm{Sr}$ was $0.06 \mu \mathrm{g} / \mathrm{g}$; concentrations of ${ }^{88} \mathrm{Sr}$ in all dentaries were well above detection limits. Strontium concentration was normalized to calcium concentration (expressed as $\mathrm{Sr}: \mathrm{Ca}, \mu \mathrm{mol} / \mathrm{mol}$ ) based on the consideration of calcium as a pseudo-internal standard (Smith and Whitledge, 2011; Rude et al., 2014). Calcium concentration $(\mu \mathrm{g} / \mathrm{g}$ ) was set at $27 \%$ based on earlier studies of fish fin ray and bone microchemistry (Smith and Whitledge, 2011; Phelps et al., 2012; Rude et al., 2014).

\section{Statistical analyses}

A one-way analysis of variance followed by Tukey's Honestly Significant Difference (HSD) test for multiple comparisons was used to assess differences in mean water $\mathrm{Sr}: \mathrm{Ca}$ among the MMR and its tributaries. Identification of natal environment for age-0 paddlefish collected in the MMR required characterization of dentary bone Sr:Ca values indicative of fish residency in each 
potential natal environment. Paddlefish of known environmental history were not available for characterization of river-specific dentary bone Sr:Ca signatures due to the lack of known spawning locations and the likelihood of fish moving among rivers within the study area prior to capture. Therefore, ranges of dentary bone $\mathrm{Sr}: \mathrm{Ca}$ for each potential natal river were estimated using water Sr:Ca data and a regression relating water and paddlefish dentary bone $\mathrm{Sr}: \mathrm{Ca}$ (Bock et al. 2016). Water Sr:Ca data were combined across all years (2006-2016) and seasons and the $5^{\text {th }}$ and $95^{\text {th }}$ percentiles of water Sr:Ca were calculated for each river. The $5^{\text {th }}$ and $95^{\text {th }}$ percentile values of water $\mathrm{Sr}: \mathrm{Ca}$ for each river were then entered into the regression relating water and dentary bone $\mathrm{Sr}: \mathrm{Ca}$ (Bock et al. 2016) and 95\% confidence limits around predicted dentary $\mathrm{Sr}: \mathrm{Ca}$ values were calculated. The $95 \%$ confidence limits around predicted dentary Sr:Ca were used as thresholds that defined the upper and lower limits of expected dentary bone $\mathrm{Sr}: \mathrm{Ca}$ for each river (Laughlin et al., 2016; Whitledge et al., 2019). Predicted ranges of dentary bone Sr:Ca for each potential natal river within the study area were used to interpret dentary bone Sr:Ca data from age-0 paddlefish collected in the MMR; dentary Sr:Ca values that fell within the predicted range for a particular river were considered indicative of the fish having occupied that river at the time that portion of the dentary bone was grown. Natal river (MMR, UMR, MOR, or tributary) was assigned to individual fish collected from the MMR by comparing dentary core Sr:Ca (first 25 $\mu \mathrm{m}$ of laser ablation transect) with predicted ranges of dentary Sr:Ca for each river.

To determine whether relative frequencies of age-0 paddlefish from different natal rivers (MMR, UMR, MOR, or tributary) differed between fish collected in the two reaches of the MMR or between collection years (2010 and 2011), a loglinear model (Poisson and negative binomial distributions and log link) with a residual scale parameter was applied. A chi-square test was then used to assess differences in relative frequencies of fish inferred to be of MMR or 
MOR origin (the two principal recruitment sources of age-0 fish caught in the MMR based on the previous analysis) between collection years and the two reaches of the MMR. All statistical analyses were performed using SAS (SAS version 9.3, Cary, NC, USA) and $a \leq 0.05$ was considered significant for all tests.

\section{RESULTS}

\section{Water chemistry}

Mean water Sr:Ca differed among rivers using all data from 2006-2016 $\left(F_{3,139}=31.93, p<\right.$ $0.0001)$ with the highest mean water Sr:Ca occurring in the MOR $(3.38 \pm 0.11 \mathrm{mmol} / \mathrm{mol})$, the MMR with an intermediate mean water $\mathrm{Sr}: \mathrm{Ca}(2.24 \pm 0.11 \mathrm{mmol} / \mathrm{mol})$, and the UMR having the lowest mean water Sr:Ca $(1.17 \pm 0.02 \mathrm{mmol} / \mathrm{mol}$; Figure 2). Mean water Sr:Ca did not differ among the Illinois, Kaskaskia, and Osage rivers $(p>0.05)$; therefore, these sites were combined into a single 'tributary' category (mean $\mathrm{Sr}: \mathrm{Ca} 1.51 \pm 0.04 \mathrm{mmol} / \mathrm{mol}$ for these three rivers combined; Figure 2). There was substantial overlap in ranges of water Sr:Ca for the UMR and tributaries. There was also some overlap in ranges of water $\mathrm{Sr}$ :Ca for the MMR and MOR; however, ranges of water Sr:Ca did not overlap for the UMR and the MMR (Figure 2).

\section{Natal environments of MMR age-0 paddlefish}

Differences in ranges of water Sr:Ca among rivers in the study area resulted in corresponding differences in predicted ranges of paddlefish dentary bone Sr:Ca characteristic of each river. Using $5^{\text {th }}$ and $95^{\text {th }}$ percentiles of water Sr:Ca for the UMR, MMR, MOR, and tributaries and the regression relating water and dentary bone $\mathrm{Sr}: \mathrm{Ca}$ (Bock et al. 2016), dentary bone $\mathrm{Sr}: \mathrm{Ca}$ values > $507 \mu \mathrm{mol} / \mathrm{mol}$ were projected to be reflective of residency in the MOR (which had the highest water Sr:Ca among potential natal rivers for age-0 paddlefish caught in the MMR). Dentary bone 
Sr:Ca values between 457 and $507 \mu \mathrm{mol} / \mathrm{mol}$ could reflect residency in either the MOR or MMR (due to overlap in ranges of water $\mathrm{Sr}: \mathrm{Ca}$ between these two rivers). Dentary bone $\mathrm{Sr}: \mathrm{Ca}$ values between 359 and $456 \mu \mathrm{mol} / \mathrm{mol}$ were predicted to be indicative of residency in the MMR, dentary Sr:Ca values between 318 and $358 \mu \mathrm{mol} / \mathrm{mol}$ could reflect residency in either the MMR, UMR, or a tributary, and dentary bone $\mathrm{Sr}: \mathrm{Ca}<318 \mu \mathrm{mol} / \mathrm{mol}$ was estimated to be characteristic of fish residing in the UMR or tributaries (Figure 3).

Among the 143 age-0 paddlefish collected from the MMR, dentary bone core Sr:Ca indicated that 44-69\% had originated in the MMR, 25-45\% of individuals collected originated in the MOR, and $2-13 \%$ of fish had originated in the UMR or a tributary (Table 1). Relative frequencies of paddlefish from different natal rivers differed between the two reaches of the $\operatorname{MMR}\left(F_{1,13}=9.82, p=0.0079\right)$ and between the two years in which fish were collected $\left(F_{1,13}=\right.$ $36.5, p<0.0001$; Table 1). Among individuals that were inferred to have originated in either the MMR or MOR, chi-square tests indicated no significant effects of reach or collection year on the relative frequencies of individuals that originated in these two rivers $(p>0.2555$; Table 1). Eight of the MOR-origin individuals had dentary bone core Sr:Ca values that were $>850 \mu \mathrm{mol} / \mathrm{mol}$.

\section{DISCUSSION}

Dentary microchemistry was effective at retrospectively describing environmental history of individual age-0 paddlefish collected in the MMR, consistent with previous research that provided evidence of the potential for dentary microchemistry to infer environmental history of paddlefish (Bock et al., 2016). Dentary microchemistry results indicated the MMR represented the principal recruitment source of MMR collected age- 0 paddlefish, with the MOR also contributing a substantial percentage of the total number of age- 0 fish sampled, and the UMR and smaller tributaries contributed relatively few individuals. Uncertainty in contributions of 
each potential natal river to age- 0 fish captured in the MMR was due to partial overlap in predicted ranges of dentary Sr:Ca among rivers (e.g., a fish with dentary core $\mathrm{Sr}: \mathrm{Ca}$ of 325 $\mu \mathrm{mol} / \mathrm{mol}$ could have originated in either the MMR, UMR, or a tributary). Estimated contributions of each natal environment to age-0 paddlefish in the MMR should be considered to be minimum estimates, as overlap among river Sr:Ca signatures did exist, and because some individuals exhibited intermediate $\mathrm{Sr}$ :Ca values and could not be definitively assigned to an individual river. Despite some uncertainty in identifying natal river for individual fish, dentary core Sr:Ca data indicated that paddlefish spawning occurred at one or more locations in both the MMR and MOR, as well as in the UMR or tributaries of the Missouri and Mississippi rivers.

Primary contributions of age-0 paddlefish from their river-of-capture (MMR) and a connected large river (MOR), with little contribution from smaller tributaries is a consistent phenomenon among large river specialist species (Phelps et al., 2012; Pracheil et al., 2013; Laughlin et al., 2016; Phelps et al., 2016; Porreca et al., 2016). Large tributaries (>166 m³/s), like the MOR to the MMR, can represent nearly all of the species richness present in the main river (Pracheil et al., 2013). For example, hard-part microchemistry revealed that large river specialist species collected in the MMR (blue catfish and adult Scaphirhynchus sturgeons) were primarily recruited from the MOR (Laughlin et al., 2016; Porreca et al., 2016). However, this study and Phelps et al. (2012) demonstrated that the MMR contributed more individuals than the MOR to age-0 paddlefish and Scaphirhynchus sturgeons sampled in the MMR (60\% MMR, 30\% MOR; Phelps et al. 2012); in both of these studies, the MOR contributed the second-highest percentage of age- 0 fish sampled from the MMR. Our finding that the majority of age-0 paddlefish collected in the MMR had dentary core $\mathrm{Sr}$ :Ca indicative of origin in either the MMR or MOR is likely related to the large size of these two rivers (MMR mean annual discharge 6056 
$\mathrm{m}^{3} / \mathrm{s}$, MOR mean annual discharge $2551 \mathrm{~m}^{3} / \mathrm{s}$; USGS, 2019d, 2019f) and their lengthy free flowing reaches (the MOR is not impounded for $1305 \mathrm{rkm}$ from Gavins Point Dam to its confluence with the Mississippi River). Although both the MMR and lower $1220 \mathrm{~km}$ of the MOR are channelized, the absence of dams in these two river reaches enhance their connectivity with one another; hydrologic connectivity is important for ecosystem function (Pringle, 2001; Pringle, 2003) and for fulfilling the life history requirements of paddlefish (Pracheil et al., 2015). Therefore, the connectivity of the MMR with the MOR may be an important factor in contributing to MMR age-0 paddlefish stocks. Further supporting this is that despite the UMR having higher annual discharge $\left(3696 \mathrm{~m}^{3} / \mathrm{s}\right.$; USGS, 2019b) than the MOR, its hydrologic connectivity with the MMR is reduced, as well as its contributions to age- 0 paddlefish in the MMR. Numerous locks and dams are found throughout the UMR, and dams are known to restrict flow and reduce both upstream and downstream movement of fishes (Liermann et al., 2012). Therefore, it is plausible that the numerous dams on the UMR are reducing the downstream drift and movement potential of age-0 paddlefish into the MMR. Furthermore, these dams may also reduce upstream movement by spawning paddlefish (Pracheil et al., 2015), which may reduce the number of recruits produced in the UMR, and subsequently affect the relative frequency of UMR-origin, age-0 paddlefish in the MMR. Previous research investigating origin of other large river specialist species (Scaphirhynchus sturgeons, blue catfish) indicated that the UMR contributed few recruits to the MMR (<10\%; Phelps et al., 2012; Porreca et al., 2016), and smaller tributaries of these systems likely had little impact (Laughlin et al., 2016).

Although hydrologic connectivity between the MMR and its large tributaries may strongly influence the contributions of paddlefish to the MMR, it is possible that different commercial fishing regulations among rivers may also affect relative contributions of different 
rivers to age- 0 paddlefish in the MMR. The commercial fishery for paddlefish is closed in the MOR, whereas the UMR is open to commercial fishing downstream of Lock and Dam 19 (Hupfeld et al., 2016). Closures in the MOR may augment the number of recruits produced in the MOR and increase probability of drift into the MMR, whereas adult stock size and recruitment in pools 20-26 of the UMR could potentially be limited to some degree by commercial harvest in this section of the river. Similar to this study, Laughlin et al. (2016) found a high contribution from the MOR and low contribution from the UMR for catfishes sampled in the MMR, which was attributed in part to a commercial fishery closure for catfishes in the MOR. Results suggest that dentary microchemistry is a potentially useful tool for assessing whether prohibition of commercial or recreational harvest of paddlefish in particular rivers may enhance the contribution of those locations to natural recruitment, provided that areas closed to harvest have chemical signatures that are distinct from locations where harvest is permitted.

We documented very little contribution of tributary origin, age-0 paddlefish to the MMR. Although paddlefish are known to inhabit the small tributaries in this study (Illinois, Kaskaskia, and Osage rivers; Pflieger, 1997; Smith, 2002), our data suggest they are of limited importance as natal sites for the age-0 paddlefish stock in the MMR. Lack of contribution from smaller tributaries to MMR age-0 large river specialist species was also documented by Laughlin et al. (2016) for catfish species. We postulate that the relatively small volume of water and habitat in smaller tributaries compared to the large rivers in this study may not be conducive for spawning, which may limit the number of recruits produced, or the number of recruits produced is small compared to those produced in the large rivers. Furthermore, the Kaskaskia, Illinois, and Osage rivers are impounded and therefore have reduced hydrologic connectivity with the mainstem rivers in this study, which may limit movement potential and spawning of paddlefish similar to 
the impoundments in the UMR. Our data suggest that tributaries are unlikely to supply substantial numbers of recruits to the MMR stock to compensate for years of poor recruit production in the MMR or the MOR. However, tributaries with greater hydrologic connectivity to the mainstem rivers may contribute to discharge increases in large rivers that provide a cue for spawning and promote recruitment of paddlefish produced in the mainstem river (Pracheil et al., 2009). When present, relatively large tributaries with long, unimpounded reaches may be important sources of recruits to large river fish populations, as has been demonstrated for shovelnose sturgeon spawned in the Wisconsin river that contribute to the UMR stock (Pracheil et al., 2019). Tributaries may also be important foraging and refuge locations for older juvenile and adult paddlefish (Pracheil et al., 2013).

Results of the log-linear model indicated there were differences in distribution of fish from different natal environment categories among river reaches and years. However, these differences were apparently driven by natal environment categories that were not specific to a particular river (e.g., MMR and MOR combined category), as the analysis that assessed differences in relative abundances of fish that were definitively of MMR or MOR origin found contributions that were consistent among years and MMR reaches. The abiotic, biotic, and temporal factors responsible for the consistent temporal and spatial patterns of natal rivers contributing to age-0 paddlefish in the MMR are unclear. Discharge during spring-summer flows (April-July) in 2010 and 2011 were both well above historical averages for the rivers examined in this study (USGS, 2019a, 2019b, 2019c, 2019d, 2019e, 2019f), with highest peak discharges during May 2011 flood. Because river discharge and current velocities likely influence drift dynamics of larval Scaphirhynchus sturgeons (Braaten et al., 2008), age-0 paddlefish may be subjected to longer drift during high discharge years. Therefore, it is possible that the observed 
consistency in natal environment contributions in this study was due to our study only encompassing years in which spring and summer discharge were consistently high. However, Laughlin et al. (2016) determined that natal environment contributions of catfishes to the MMR were consistent among multiple years with variable discharge. Variable discharge may also affect paddlefish spawning dynamics as certain conditions may not be met annually, and individuals may not spawn annually (Jennings, 2009), which may affect natal environment contributions to MMR paddlefish populations. To improve our understanding of paddlefish recruitment and the factors that influence contributions from river, additional years of data with variable discharge will be needed. Furthermore, implementing studies that examine natal rivers that contribute to age-0 paddlefish stocks downstream of our study area in the MMR (in the lower Mississippi River, located downstream of the mouth of the Ohio River), may facilitate estimates of drift distance of paddlefish originating from the MOR (or other rivers with a distinct chemical signature compared to downriver locations). We found eight fish with very high dentary core $\mathrm{Sr}: \mathrm{Ca}(>850 \mu \mathrm{mol} / \mathrm{mol})$ that may have originated in the MOR $>625 \mathrm{rkm}$ upstream of the MOR-MMR confluence based on the regression relating water Sr:Ca and paddlefish dentary Sr:Ca developed by Bock et al. (2016). Substantial downstream passage by paddlefish through Fort Randall and Gavins Point dams into the lower, unimpounded reach of the MOR has been documented (Pracheil et al. 2015) and may account for at least some of the fish with very high dentary core Sr:Ca collected in the MMR. How drift distances change annually would be valuable for understanding paddlefish drift dynamics; however, more data are needed regarding temporal variability in the upstream-downstream gradient in water $\mathrm{Sr}$ :Ca in the lower Missouri River (Phelps et al. 2012) to potentially enable estimation of drift distances by individual paddlefish. 
This study highlights the importance of managing and conserving paddlefish stocks interjurisdictionally. Our results suggest MMR-collected age-0 paddlefish originate from primarily within the MMR, but its large principal tributaries like the MOR are important for maintaining recruits within the MMR. This study, coupled with research on large scale movements of adult paddlefish (Stancill et al., 2002; Pracheil et al., 2012; Tripp et al., 2014; Tripp et al., 2019), indicates that paddlefish populations should be managed at a basin-wide level to effectively protect and conserve paddlefish populations at all life history stages (Pracheil et al., 2012; Hupfeld et al., 2016). Furthermore, dentary microchemistry could be applied to adults to determine environmental history and potential inter-river movements (Bock et al., 2016). Dentary microchemistry may allow researchers to determine the percentage of recruits from a given river that support adult stocks in the MMR or other rivers, as it may be different from what is observed in age- 0 fish, as has been observed in previous research investigating natal rivers of larval (Phelps et al., 2012), and adult Scaphirhynchus sturgeons (Porreca et al., 2016). Further understanding of the importance of particular rivers as natal environments supporting paddlefish populations will complement telemetry and tagging studies on adult fish (Pracheil et al. 2012; Tripp et al. 2014) in informing identification and protection of spawning areas and ascertaining when and where maintenance or restoration of connectivity between river reaches and habitats used by paddlefish for spawning and during early life stages is needed to support recruitment sufficient to sustain paddlefish populations in large river systems.

\section{ACKNOWLEDGEMENTS}

We thank Sara Tripp and the Missouri Department of Conservation for providing paddlefish and collection information for this project, and Lindsey Bock for laboratory analysis of dentary samples. We also thank Alan Shiller of the Center for Trace Analysis, University of 
Southern Mississippi for analysis of Sr and Ca concentrations in water samples, and the Environmental Analytical Facility at the University of Massachusetts-Boston for use of their ICPMS for analysis of dentary Sr:Ca.

\section{DATA AVAILABILITY STATEMENT}

The data that support the findings of this study are available from the corresponding author upon reasonable request. 


\section{REFERENCES}

Abell, N. J., Oliver, D. C., \& Whitledge, G. W. (2018). Recruitment sources and spatial patterns of population demographics of spotted bass in a large river-tributary network. Fisheries Management and Ecology, 25, 339-349.

Adams, L. A. (1942). Age determination and rate of growth in Polyodon spathula, by means of the growth rings of the otoliths and dentary bone. The American Midland Naturalist, 28, 617-630.

Bettoli, P. W., Kerns, J. A., \& Scholten, G. D. (2009). Status of paddlefish in the United States. In C. Paukert, \& G. Scholten (Eds.) Paddlefish Management, Propagation, and Conservation in the 21st Century Building from 20 Years of Research and Management (pp. 23-38). Bethesda, MD: American Fisheries Society.

Bock, L., Whitledge, G., Pracheil, B., \& Bailey, P. (2016). Relationships between water and paddlefish Polyodon spathula dentary elemental and stable-isotopic signatures: potential application for reconstructing environmental history. Journal of Fish Biology, 90, 595610.

Braaten, P. J., Fuller, D. B., Holte, L. D., Lott, R. D., Viste, W., Brandt, T. F., \& Legare, R. G. (2008). Drift dynamics of larval pallid sturgeon and shovelnose sturgeon in a natural side channel of the upper Missouri River, Montana. North American Journal of Fisheries Management, 28, 808-826.

Brown, R. S., Cooke, S. J., Anderson, W. G., \& McKinley, R. S. (1999). Evidence to challenge the " $2 \%$ rule" for biotelemetry. North American Journal of Fisheries Management, 19, $867-871$. 
Cooke, S. J., Martins, E. G., Struthers, D. P., Gutowsky, L. F. G., Power, M., Doka, S. E., ... Kruger, C. C. (2016). A moving target - incorporating knowledge of the spatial ecology of fish into assessment and management of freshwater fish populations. Environmental Monitoring and Assessment, 188, 1-18.

Davis, M. C., Shubin, N. H., \& Force, A. (2004). Pectoral fin and girdle development in the basal actinopterygians Polyodon spathula and Acipenser transmontanus. Journal of Morphology, 262, 608-628.

Fausch, K. D., Torgersen, C. E., Baxter, C. V., \& Li, H. W. (2002). Landscapes to Riverscapes: Bridging the Gap between Research and Conservation of Stream Fishes: A Continuous View of the River is Needed to Understand How Processes Interacting among Scales Set the Context for Stream Fishes and Their Habitat. BioScience, 52, 483-498.

Hanski, I., \& Gilpin, M. E. (1997). Metapopulation Biology: Ecology, Genetics, and Evoloution. San Diego, CA: Academic press.

Herzog, D. P., Barko, V. A., Scheibe, J. S., Hrabik, R. A., \& Ostendorf, D. E. (2005). Efficacy of a benthic trawl for sampling small-bodied fishes in large river systems. North American Journal of Fisheries Management, 25, 594-603.

Hupfeld, R. N., Phelps, Q. E., Tripp, S. J., \& Herzog, D. P. (2016). Mississippi River Basin Paddlefish Population Dynamics: Implications for the Management of a Highly Migratory Species. Fisheries, 41, 600-610.

Jennings, C. A., \& Zigler, S. J. (2009). Biology and life history of paddlefish in North America: an update. In C. Paukert, \& G. Scholten (Eds.) Paddlefish Management, Propagation, and Conservation in the 21st Century Building from 20 Years of Research and Management (pp. 1-22). Bethesda, MD: American Fishereis Society. 
Jepsen, N., Schreck, C., Clements, S., \& Thorstad, E. (2005). A brief discussion on the 2\% tag/bodymass rule of thumb. In M. Spedicato, G. Marmulla, \& G. Lembo (Eds.) Aquatic telemetry: advances and applications (pp. 255-259). Rome, Italy: FAO-COISPA.

Kennedy, B. P., Klaue, A., Blum, J. D., Folt, C. L., \& Nislow, K. H. (2002). Reconstructing the lives of fish using Sr isotopes in otoliths. Canadian Journal of Fisheries and Aquatic Sciences, 59, 925-929.

Laughlin, T. W., Whitledge, G., Oliver, D. C., \& Rude, N. P. (2016). Recruitment sources of channel and blue catfishes inhabiting the middle Mississippi River. River Research and Applications, 32, 1808-1818.

Liermann, C. R., Nilsson, C., Robertson, J., \& Ng, R. Y. (2012). Implications of dam obstruction for global freshwater fish diversity. BioScience, 62, 539-548.

Ludsin, S. A., Fryer, B. J., \& Gagnon, J. E. (2006). Comparison of solution-based versus laser ablation inductively coupled plasma mass spectrometry for analysis of larval fish otolith microelemental composition. Transactions of the American Fisheries Society, 135, 218231.

Pflieger, W. (1997). The fishes of Missouri, rev. ed. Jefferson City, MO: Missouri Department of Conservation.

Phelps, Q. E., Tripp, S., Garvey, J., Herzog, D., Ostendorf, D., Ridings, J., Crites, J., \& Hrabik, R. (2009). Ecology and habitat use of age-0 paddlefish in the unimpounded middle Mississippi River. In C. S. Paukert, GD (Ed.) Paddlefish Management, Propagation, and Conservation in the 21st Century: Building from 20 Years of Research and Management (pp. 423-440). Bethesda, MD: American Fisheries Society. 
Phelps, Q. E., Whitledge, G. W., Tripp, S. J., Smith, K. T., Garvey, J. E., Herzog, D. P., Ostendorf, D. E., Ridings, J. W., Crites, J. W., \& Hrabik, R. A. (2012). Identifying river of origin for age-0 Scaphirhynchus sturgeons in the Missouri and Mississippi rivers using fin ray microchemistry. Canadian Journal of Fisheries and Aquatic Sciences, 69, 930941.

Phelps, Q., Hupfeld, R., \& Whitledge, G. (2016). Lake sturgeon Acipenser fulvescens and shovelnose sturgeon Scaphirhynchus platorynchus environmental life history revealed using pectoral fin-ray microchemistry: implications for interjurisdictional conservation through fishery closure zones. Journal of Fish Biology, 90, 626-639.

Porreca, A. P., Hintz, W. D., Whitledge, G. W., Rude, N. P., Heist, E. J., \& Garvey, J. E. (2016). Establishing ecologically relevant management boundaries: linking movement ecology with the conservation of Scaphirhynchus sturgeon. Canadian Journal of Fisheries and Aquatic Sciences, 73, 877-884.

Pracheil, B. M., Pegg, M. A., \& Mestl, G. E. (2009). Tributaries influence recruitment of fish in large rivers. Ecology of Freshwater Fish, 18, 603-609.

Pracheil, B. M., Pegg, M. A., Powell, L. A., \& Mestl, G. E. (2012). Swimways: protecting paddlefish through movement-centered management. Fisheries, 37, 449-457.

Pracheil, B. M., McIntyre, P. B., \& Lyons, J. D. (2013). Enhancing conservation of large-river biodiversity by accounting for tributaries. Frontiers in Ecology and the Environment, 11, 124-128.

Pracheil, B., Mestl, G., \& Pegg, M. (2015). Movement through dams facilitates population connectivity in a large river. River Research and Applications, 31, 517-525. 
Pringle, C. M. (2001). Hydrologic connectivity and the management of biological reserves: a global perspective. Ecological Applications, 11, 981-998.

Pringle, C.M. (2003). What is hydrologic connectivity and why is it ecologically important? Hydrological Processes, 17, 2685-2689.

Rude, N. P., Smith, K. T., \& Whitledge, G. W. (2014). Identification of stocked muskellunge and potential for distinguishing hatchery-origin and wild fish using pelvic fin ray microchemistry. Fisheries Management and Ecology, 21, 312-321.

Scarnecchia, D. L., Ryckman, L. F., Lim, Y., Power, G., Schmitz, B., \& Riggs, V. (2006). A long-term program for validation and verification of dentaries for age estimation in the Yellowstone-Sakakawea paddlefish stock. Transactions of the American Fisheries Society, 135, 1086-1094.

Scholten, G. D., \& Bettoli, P. W. (2005). Population characteristics and assessment of overfishing for an exploited paddlefish population in the lower Tennessee River. Transactions of the American Fisheries Society, 134, 1285-1298.

Shiller, A. M. (2003). Syringe filtration methods for examining dissolved and colloidal trace element distributions in remote field locations. Environmental Science \& Technology, 37, 3953-3957.

Smith, K. T., \& Whitledge, G. (2011). Trace element and stable isotopic signatures in otoliths and pectoral spines as potential indicators of catfish environmental history. In P. Michaletz, \& V. Travnichick (Eds.) Conservation, Ecology, and Management of Catfish: The Second International Symposium (pp. 645-660). Bethesda, MD: American Fisheries Society. 
Smith, P. W. (2002). The fishes of Illinois. Urbana and Chicago, IL: University of Illinois Press.

Stancill, W., Jordan, G. R., \& Paukert, C. P. (2002). Seasonal migration patterns and site fidelity of adult paddlefish in Lake Francis Case, Missouri River. North American Journal of Fisheries Management, 22, 815-824.

Tripp, S., Brooks, R., Herzog, D., \& Garvey, J. (2014). Patterns of fish passage in the Upper Mississippi River. River Research and Applications, 30, 1056-1064.

Tripp, S. J., Phelps, Q. E., Hupfeld, R. N., Herzog, D. P., Ostendorf, D. E., Moore, T. L., Brooks, R. C., \& Garvey, J. E. (2019). Sturgeon and Paddlefish Migration: Evidence to Support the Need for Interjurisdictional Management. Fisheries, 44, 183-193.

USGS (United States Geological Survey) 2019a. National Water Information System: Web Interface data available on the World Wide Web (USGS Water Data for the Nation), accessed January 17, 2019, at URL https://waterdata.usgs.gov/il/nwis/uv/?site_no=05586100

USGS (United States Geological Survey) 2019b. National Water Information System: Web Interface data available on the World Wide Web (USGS Water Data for the Nation), accessed January 17, 2019, at URL https://waterdata.usgs.gov/i1/nwis/uv/?site_no=05587450

USGS (United States Geological Survey) 2019c. National Water Information System: Web Interface data available on the World Wide Web (USGS Water Data for the Nation), accessed January 17, 2019, at URL https://waterdata.usgs.gov/il/nwis/uv/?site_no=05595000 
USGS (United States Geological Survey) 2019d. National Water Information System: Web Interface data available on the World Wide Web (USGS Water Data for the Nation), accessed January 17, 2019, at URL https://waterdata.usgs.gov/i1/nwis/uv/?site_no=07020500

USGS (United States Geological Survey) 2019e. National Water Information System: Web Interface data available on the World Wide Web (USGS Water Data for the Nation), accessed January 17, 2019, at URL https://waterdata.usgs.gov/mo/nwis/uv/?site_no=06926510

USGS (United States Geological Survey) 2019f. National Water Information System: Web Interface data available on the World Wide Web (USGS Water Data for the Nation), accessed January 17, 2019, at URL https://waterdata.usgs.gov/mo/nwis/uv/?site_no=06935965

Whitledge, G. W., Knights, B., Vallazza, J., Larson, J., Weber, M. J., Lamer, J. T., Phelps, Q. E., \& Norman, J. D. (2019). Identification of Bighead Carp and Silver Carp early-life environments and inferring Lock and Dam 19 passage in the Upper Mississippi River: insights from otolith chemistry. Biological Invasions, 21, 1007-1020.

Woodcock, S. H., Grieshaber, C. A., \& Walther, B. D. (2013). Dietary transfer of enriched stable isotopes to mark otoliths, fin rays, and scales. Canadian Journal of Fisheries and Aquatic Sciences, 70, 1-4.

Wuellner, M., Grote, J., \& Fincel, M. (2017). Spatial and temporal distinction of microelemental signatures of Missouri River tributaries. River Research and Applications, 33, 632-638. 
Zeigler, J. M., \& Whitledge, G. W. (2010). Assessment of otolith chemistry for identifying source environment of fishes in the lower Illinois River, Illinois. Hydrobiologia, 638, 109-119.

Zeigler, J. M., \& Whitledge, G. W. (2011). Otolith trace element and stable isotopic compositions differentiate fishes from the Middle Mississippi River, its tributaries, and floodplain lakes. Hydrobiologia, 661, 289-302. 
Table 1. Natal environment classification for middle Mississippi River collected age-0 paddlefish $(\mathrm{n}=143)$ during 2010-2011 determined from dentary core Sr:Ca values for individual fish. Number of fish (numbers in parentheses are percentages) by reach and sampling year classified to a natal environment (UMR_TRIB = upper Mississippi River or small tributaries that include the Illinois, Kaskaskia, and Osage rivers; MMR_UMR_TRIB = middle Mississippi River or upper Mississippi River or small tributaries; MMR = middle Mississippi River; MOR_MMR $=$ Missouri River or middle Mississippi River; MOR = Missouri River).

\begin{tabular}{|c|c|c|c|}
\hline Reach & Natal Environment & \multicolumn{2}{|c|}{ Sampling Year } \\
\hline & & 2010 & 2011 \\
\hline 1 & UMR_TRIB & $3(8.3)$ & $0(0.0)$ \\
\hline 1 & MMR_UMR_TRIB & $8(22.2)$ & $1(7.1)$ \\
\hline 1 & MMR & $15(41.7)$ & $7(50.0)$ \\
\hline 1 & MOR_MMR & $5(13.9)$ & $1(7.1)$ \\
\hline 1 & MOR & $5(13.9)$ & $5(35.7)$ \\
\hline 2 & UMR_TRIB & $0(C$ & $0(0.0)$ \\
\hline 2 & MMR_UMR_TRIB & $6(7.5)$ & $1(7.7)$ \\
\hline 2 & MMR & $35(43.8)$ & $6(46.2)$ \\
\hline 2 & MOR_MMR & $10(12.5)$ & $4(30.8)$ \\
\hline 2 & MOR & $29(36.3)$ & $2(15.4)$ \\
\hline
\end{tabular}


Figure Legends.

Figure 1. Map of the Mississippi River and principal tributaries in Illinois and Missouri, USA showing potential natal rivers for age-0 paddlefish sampled from the Middle Mississippi River (section of the Mississippi River between the mouths of the Missouri and Ohio rivers). Age-0 paddlefish were collected from two river reaches: Reach 1 extended from the mouth of the Missouri River to the mouth of the Kaskaskia River; Reach 2 extended from the mouth of the Kaskaskia River to the Mississippi-Ohio River confluence.

Figure 2. Boxplots displaying the ranges, means, and interquartile ranges for water $\mathrm{Sr}: \mathrm{Ca}$ from potential natal environments for age-0 paddlefish collected from the middle Mississippi River (MMR). Water samples were collected during summer from 2006-2016 from the MMR, upper Mississippi River (UMR), Missouri River (MOR), and tributaries (Illinois, Kaskaskia, and Osage rivers).

Figure 3. Example patterns of dentary $\mathrm{Sr}: \mathrm{Ca}$ along laser ablation transects from three age-0 paddlefish collected from the middle Mississippi River (MMR), including a fish that originated in the MMR (light gray line), a fish that originated in the Missouri River and subsequently moved into the MMR (black line), and a fish that originated in the upper Mississippi River or a small tributary and moved into the MMR (dark gray line). Dashed lines indicate $\mathrm{Sr}: \mathrm{Ca}$ thresholds that distinguish natal environment categories from one another (MOR $=$ Missouri River; MOR_MMR = Missouri River or middle Mississippi River; MMR $=$ middle Mississippi River; MMR_UMR_TRIB = middle Mississippi River or upper Mississippi River or small tributary; UMR_TRIB = upper Mississippi River or small tributaries that include the Illinois, Kaskaskia, and Osage rivers). 


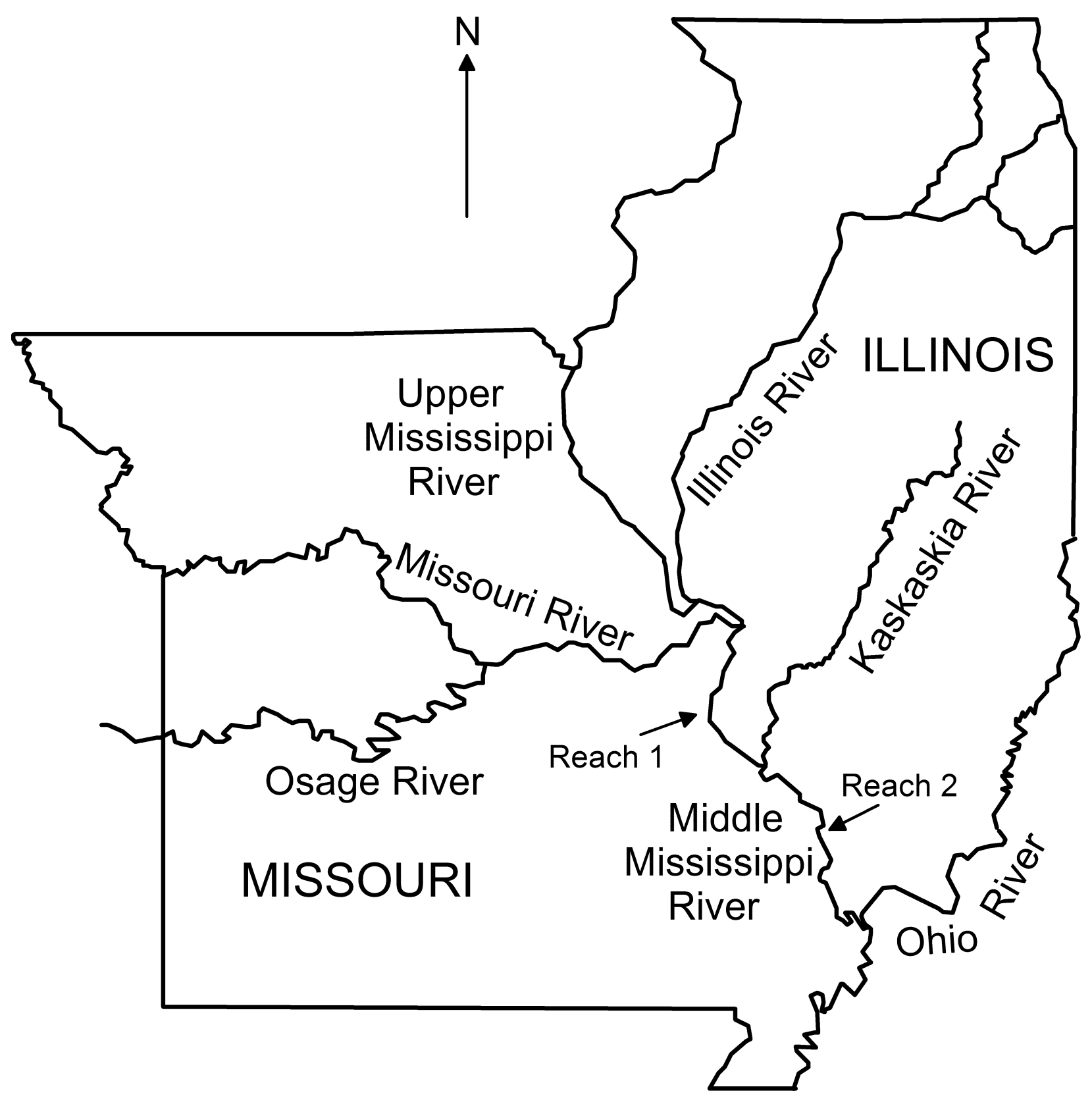

Figure 1 


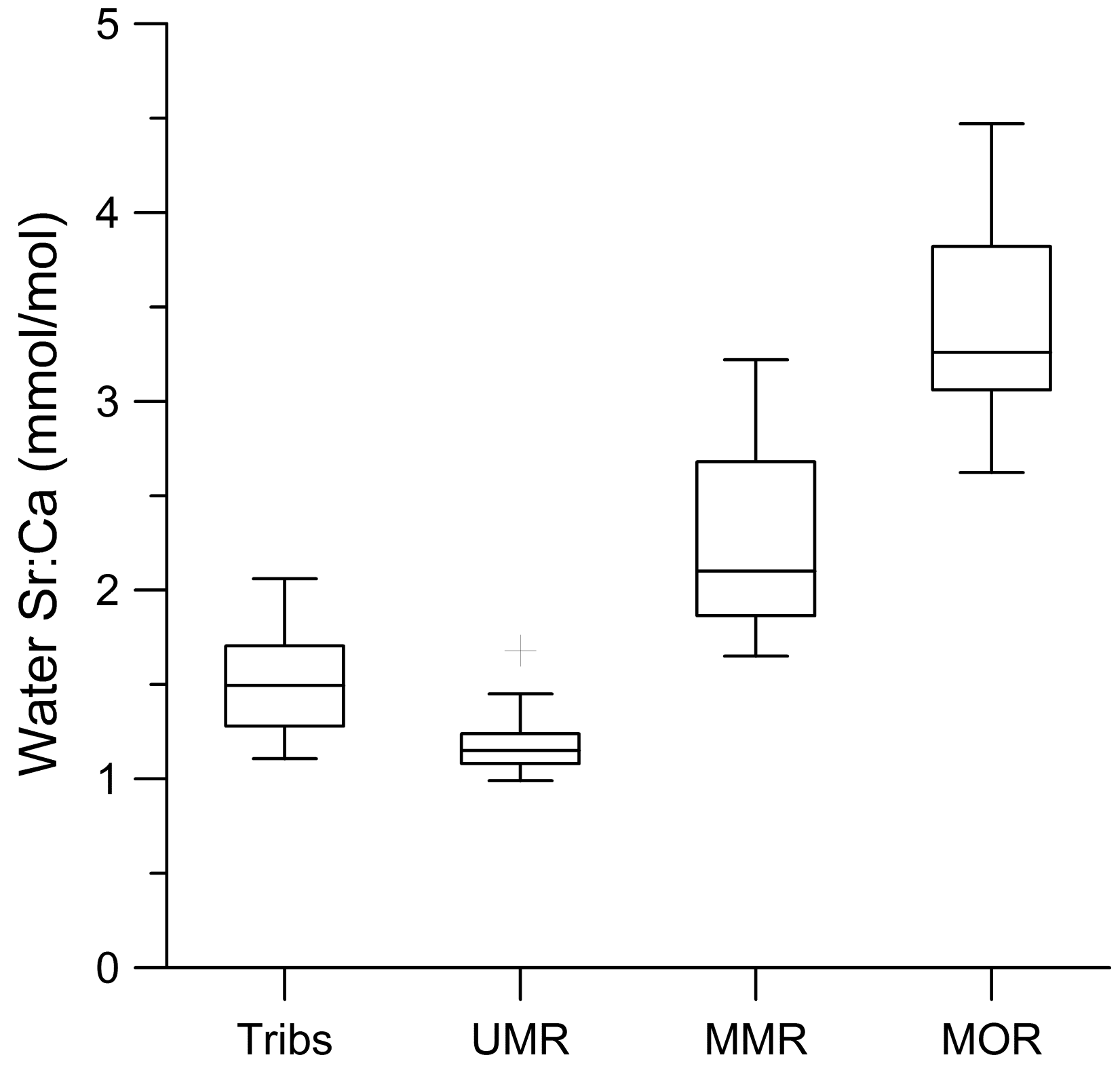

Figure 2 


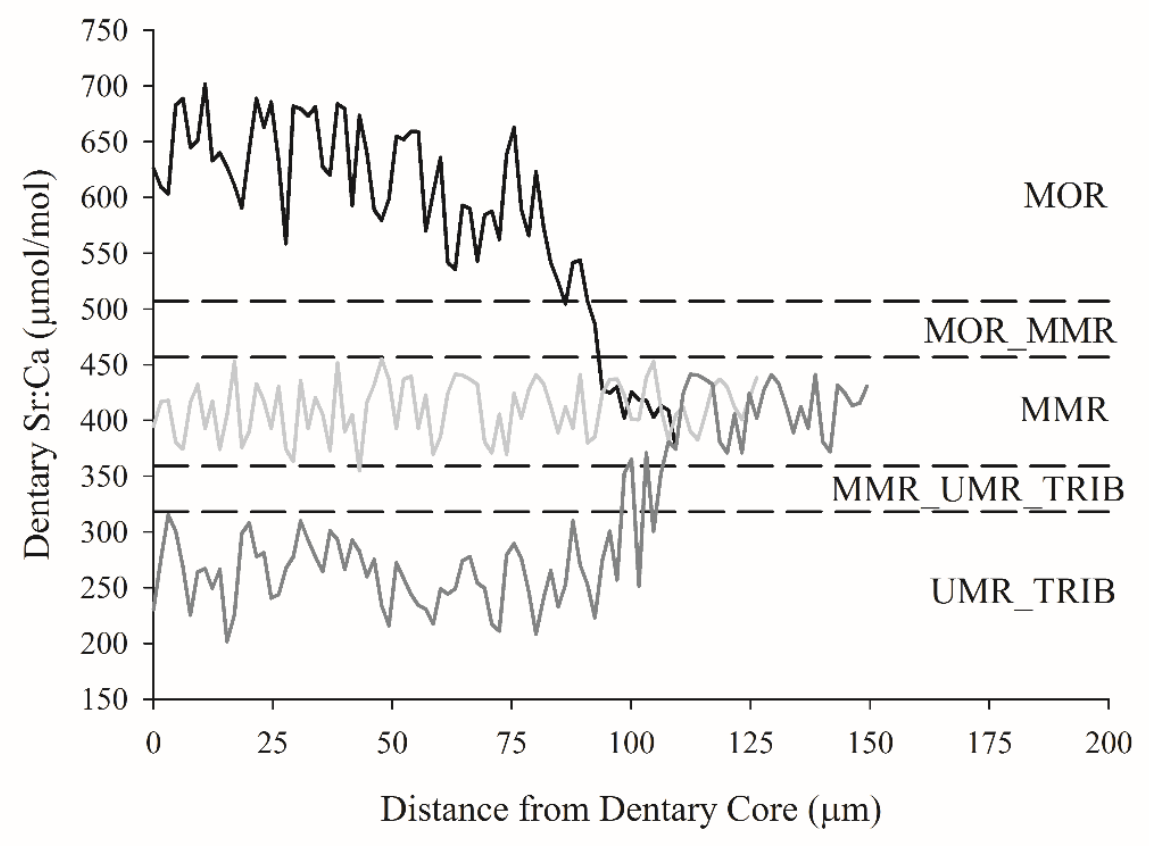

Figure 3 